\title{
Türkiye Kıyılarında Bulunan Pelajik Ketognat Türlerinin Tayin Anahtarı
}

\section{Tuba TERBIYIK KURT ${ }^{*}$, Sevim POLAT}

Çukurova Üniversitesi, Su Ürünleri Fakültesi, Temel Bilimler Bölümü, Adana, Türkiye

*Sorumlu Yazar: tubaterbiyik@gmail.com

Geliş 14 Aralık 2018; Kabul 15 Şubat 2019; Basım 01 Haziran 2019.

Alıntılama: Terbıyık Kurt, T., \& Polat, S. (2019). Türkiye kıyılarında bulunan pelajik ketognat türlerinin tayin anahtarı. Acta Aquatica Turcica, 15(2), 227-238. https://doi.org/10.22392/actaquatr.497205

\section{Özet}

$\mathrm{Bu}$ çalışma, Türkiye kıyısal sularında bulunan pelajik ketognat türleri için yapılmış ilk tayin anahtarıdır. Tayin anahtarının hazırlanması sırasında kişisel gözlemlerden ve daha önce yapılmış çalışmalardan elde edilen bilgilerden yararlanılmıştır. Ülkemiz kıyılarında yapılan çalışmalar sonucunda, 9 cinse ait toplam 13 ketognat türünün dağılım gösterdiği tespit edilmiştir. Mevcut çalışmada tayin anahtarı ile birlikte, bu türlerin morfolojik ve dağılım özellikleri de verilerek ülkemiz sularında yapılacak yeni çalışmalara kaynak olması amaçlanmıştır.

Anahtar kelimeler: Pelajik ketognatlar, tayin anahtarı, morfolojik karakterler, Türkiye

Identification key of pelagic chaetognath species along Turkish coasts

\begin{abstract}
This study is the first attempt to create the identification key of pelagic chaetognath species inhabited in coastal waters of the Turkey. During the preparation of this identification key, personal observations and information obtained from previous studies were used. As a result of the studies performed on the coasts of Turkey, it was observed that a total of 13 chaetognath species of 9 genera were distributed along the Turkish coasts. In the present study, their morphological and distributional characteristics were presented together with identification key and it was aimed to be base references for further studies.
\end{abstract}

Keywords: Pelagic chaetognaths, identification key, morphological characters, Turkey

\section{GíRiş}

Ketognatlar denizel ekosistemlerde yaygın dağılım gösteren ve 200'den fazla türü bulunan bir şubedir (Bierri, 1991). Bu canlıların boyutları küçük olmasına karşın, ikincil tüketiciler olarak pelajik besin ağında önemli rol oynamaktadır (Casanova, 1999). Zooplankton içinde en yaygın bulunan gruplardan olan ketognatlar, bolluk bakımından da kommunitede bazen kopepodlardan sonra ikinci ya da üçüncü sırada yer almaktadır. Reeve (1970) dünya okyanuslarında ketognat biyokütlesinin toplam kopepod biyokütlesinin \% 30'una kadar ulaşabilen oranlarda bulunduğunu bildirmiştir.

Ketognatlar morfolojileri ve yüzme şekillerinden dolayı genellikle ok kurtları ya da mızrak solucanları olarak bilinirler. Bununla birlikte, latincede kıl diken anlamına gelen "chaeto" ve çene anlamına gelen "gnathos" kelimelerden türemiştir ve kıllı çeneliler (Chaetognatha) anlamına gelmektedir. Vücutları bilateral simetrili olup, enterosölomlu hayvanlardır (Hyman, 1957). Embriyonik gelişimleri bakımından ise deuterostoma (ikincil ağızlılar) içinde yer almaktadır (Zgang, 1988). Bu canlıların belirsiz filogenetik kökeni (Szaniawski, 2002) ve diğer şubelerle olan ilişkisi diğer hayvan gruplarından taksonomik olarak izole olduğunu gösterir (Casanova, 1999).

Türkiye kıyılarında ketognatlar ile ilgili çalışmalar yeterli düzeyde olmamakla birlikte, bunun en önemli sebeplerinden birisi tanı ve teşhisleri için yeterli kaynak bulunmamasıdır (İşmen, 2000; Üstün, 2005; Beşiktepe, 2000; Mutlu, 2005; Hazar, 2006; Terbıyık vd. 2007; Terbıyık ve Sarıhan, 2008; Terbıyık Kurt ve Polat, 2013; Kurt, 2016; Terbıyık Kurt, 2018). Türkiye sularında bu güne değin kayıt edilmiş ve gözlenmiş 9 cinse ait toplam 13 ketognat türü bulunmaktadır. Bu çalışmada, Türkiye kıyılarında bulunan ketognatların tanı anahtarı ve karakteristik özellikleri verilerek, ileride yapılacak çalışmalara katkıda bulunulması amaçlanmıştır. 


\section{MATERYAL ve YÖNTEM}

$\mathrm{Bu}$ çalışmada kişisel gözlemlerimiz ve daha önce yapılmış çalışmalardan verilen tanımlamalardan yararlanılmıştır. (Michel, 1984; Pierrot-Bults ve Chidgey, 1988; Mc Lelland,1989; Bierri, 1991; Kehayias vd., 1999; Casanova, 1999). Ketognat örnekleri İskenderun Körfezi kıy1- açık bölgelerinden ağ göz açıklığ $200 \mu \mathrm{m}$ olan WP2 model standart zooplankton kepçesi kullanılarak alınmıştır. Toplanan örnekler \% 4'lük tamponlanmış formaldehit eklenerek korunmuştur. Türlerin sınıflandırılması aşamasında WoRMS veri tabanı kullanılmıştır.

\section{Genel Morfolojisi}

Ketognatlar uzamış, ince tüp şeklinde ve silindirik yapıdadır (Casanova, 1999). Genellikle saydam olan bu canlılardan bazıları fiksasyondan sonra opak olabilmektedir (Conway, 2015). Bu canlılar, türlere özgü olarak saydam ya da mat ve yumuşak ya da sert yapıda olabilmektedir. Vücutları 3 bölümden oluşur: Baş, gövde ve kuyruk (Şekil 1.A). Baş, yuvarlak, hafifçe yassılaşmış olup her iki tarafında yakalama çengelleri, vestübülar organ, ön ve arka dişleri taşır (Şekil 1. B). Ağız açıklığı başın ventral bölgesinde yer almaktadır. Dorsal kısmında bir çift göz ve gövde segmentine doğru uzayan silli lop (corona cilliata) bulunur (Şekil 1.C). Baş, gövde segmentinden dar bir boyun ile ayrılmıştır. Gövde segmentinde bağırsak, bağırsak divertikülü, yaka, ventral gangliyon, yumurtalıklar, anüs açılığı, ön yüzgeçler ve arka yüzgeçlerin bir bölümü yer almaktadır (Pierrot- Bults \& Chidgey, 1988). Gövde segmenti kuyruk bölmesi ile kuyruk segmentinden ayrılmaktadır. Kuyruk segmentinde ise arka yüzgeçlerin bir bölümü, seminal keseler ve kuyruk yüzgeci bulunur (Şekil 1A).

\section{Ketognat Türleri ve Tanıları}

Ülkemiz kıyılarının çeşitli bölgelerinde (Karadeniz, Marmara, Akdeniz) ketognatlarla ilgili çalışmalar mevcut olup (İşmen, 2000; Üstün, 2005; Beşiktepe, 2000; Mutlu, 2005; Hazar, 2006; Terbıyık vd. 2007; Terbıyık ve Sarıhan, 2008; Terbıyık Kurt ve Polat, 2013; Kurt, 2016; Terbiyık Kurt, 2018), 9 cinse ait toplam 13 ketognat türü dağılım göstermektedir. Bunların sinıflandırmalı listesi aşağıda verilmiştir.

Alem: Animalia

Şube: Chaetognatha

Sinif: Sagittoidea

Takım: Aphragmophora

Familya: Krohnittidae Tokioka, 1965

Cins: Krohnitta Ritter-Záhony, 1910

Krohnitta subtilis (Grassi, 1881)

Familya: Sagittidae Claus and Groben, 1905

Cins: Decipisagitta Bieri, 1991

Decipisagitta decipiens (Fowler, 1905)

Cins: Ferosagitta Kassatkina, 1971

Ferosagitta galerita (Dallot, 1971)

Cins: Flaccisagitta Tokioka, 1965

Flaccisagitta enflata (Grassi, 1881)

Flaccisagitta hexaptera (dÕOrbigny, 1836)

Cins: Mesosagitta Tokioka, 1965

Mesosagitta minima (Grassi, 1881)

Cins: Parasagitta Tokioka, 1965

Parasagitta friderici (Ritter-Záhony, 1911)

Parasagitta megalophthalma (Dallot and Ducret, 1969)

Parasagitta setosa (J. Müller, 1847)

Parasagitta tenuis (Conant, 1896)

Cins: Pseudosagitta Germain \& Joubin, 1912

Pseudosagitta lyra (Krohn, 1853)

Cins: Sagitta Quoy \& Gaimard, 1827

Sagitta bipunctata Quoy and Gaimard, 1827 
Cins: Serratosagitta Tokioka, 1965

Serratosagitta serratodentata (Krohn, 1853)

Ketognatların vücut yapısı ve uzantıları karakteristik özellik olduğundan tür tanısında kolaylıkla kullanılabilmektedir. Aslında ketognatlardaki morfolojik çeşitlilik bilinenden daha fazla olup, yeni keşfedilen türlerde daha farklı yapılarında varlığı rapor edilmiştir (Dallot, 1970; Owre, 1973; Zhang ve Chen, 1983; Casanova, 1985;). Bununla birlikte, tayin anahtarının hazırlanmasındaki başlıca kural, çoğu türlerde kolaylıkla gözlenebilen genel karakterler ile başlamak ve tür sayısını azaltıcı karakterlerle devam etmektir (Kehayias vd., 1999; Terbıyık ve Sarıhan, 2007). Mevcut tanı anahtarı oluşturulurken özellikle rahatlıkla görülebilen ve belirgin morfolojik karakterler kullanılmıştır. Ketognatlarda ön, arka ve kuyruk yüzgeçlerinin şekli ve pozisyonu, ş̧ınların dağılımı, ön ve arka dişlerin sayısı, göz pigmentlerinin şekli ve büyüklüğ̈̈; yakanın varlığı ve şekli; bağırsak divertikülünün varlığı, çengellerin şekli ve sayısı, vücut bölümlerinin oranı, seminal kesenin şekli ve yüzgeçler arasındaki pozisyonu, yumurtalıkların yapısı ve uzunluğu ile yumurtanın büyüklüğü tür teşhisinde kullanılan başlıca morfolojik yapılardır (Alvarino, 1967; Michel, 1984; Terbıyık ve Sarıhan, 2007). Fakat, bazı karakterlerin sadece olgunluk aşamasında görülebilmesi (örneğin seminal kese, yumurtalıklar) tür tayinini zorlaştırabilmektedir.

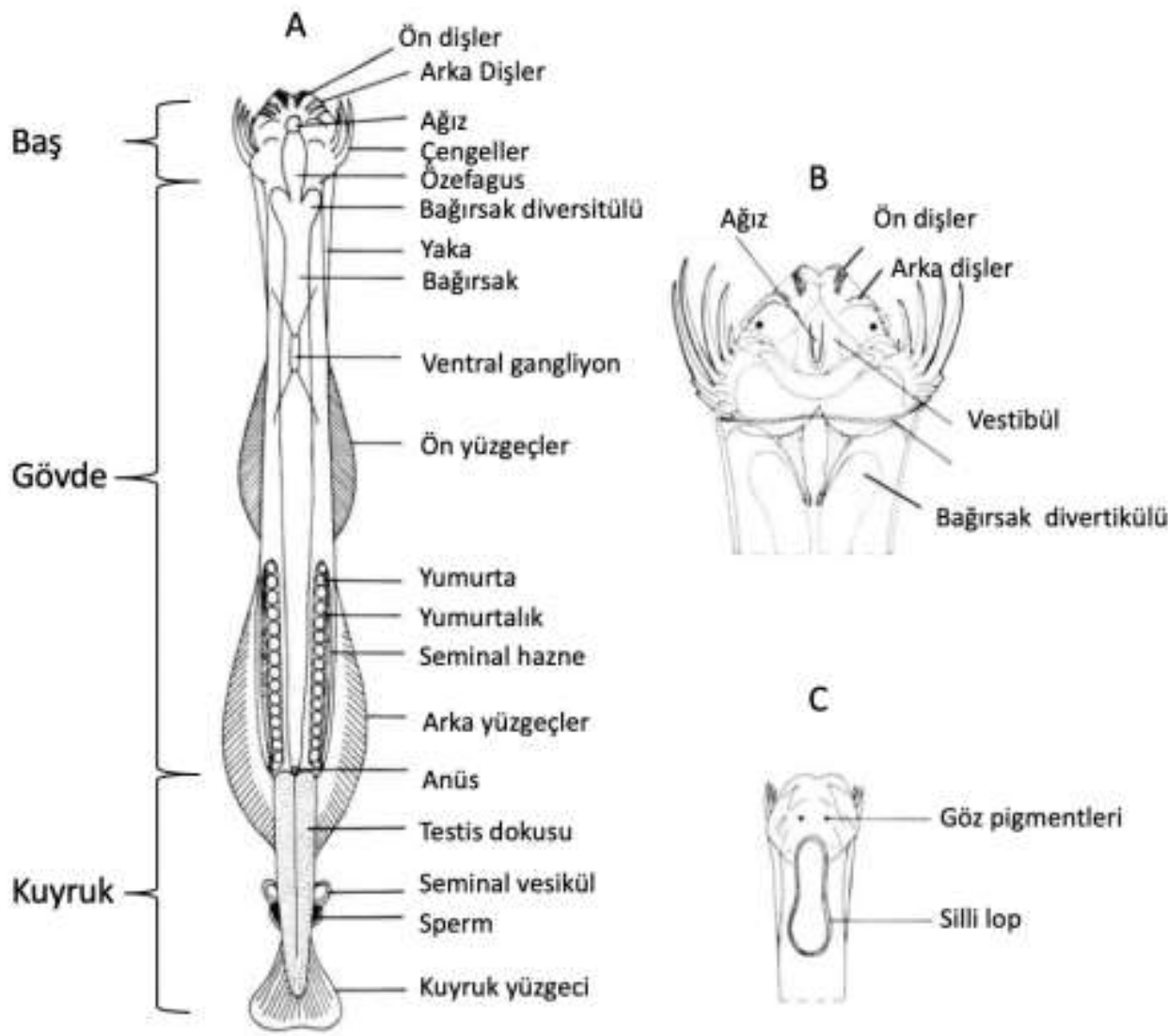

Şekil 1. A. Ketognatların genel dış yapısı, B. Baş yapısı, C. Silli Lop görünümü (Pierrot-Bult ve Chidgey, 1988'dan alınmıştır).

Ketognat türlerinin tanımlanmasında kullanılan çeşitli tayin anahtarları mevcuttur (Fraser, 1957; Furnestin, 1957; Tregouboff ve Rose, 1957; Alvarino, 1967; Kasatkina,1982; Michel, 1984; McLelland, 1989; Bierri, 1991; Casanova, 1999). Akdeniz'de dağılım gösteren türler için ise Kehayias vd. (1999) oldukça kullanışlı bir tanı anahtarı geliştirmiştir. Fakat bu tayin anahtarı son yıllarda ülkemiz kıyılarından rapor edilen Ferosagitta galerita türünü içermemektedir (Terbıyık vd., 2007). Mevcut tayin anahtarında ise Türkiye kıyılarında gözlenen ketognat türleri ele alınmıştır. Tayin anahtarı hazırlanırken Alvarino (1967); Dallot (1971); Michel (1984); Pierrot-Bult \& Chidgey (1988); Zhong (1988); Mc Lelland, (1989); Bierri (1991); Casanova, (1999); Kehayias vd., (1999), Casanova (1999) ve Terbıyık vd. (2007)'den yararlanılmıştır. Tür teşhisleri sırasında, ketognat bireyleri 
öncelikle tayin anahtarı takip edilerek tür düzeyinde belirlenmeli, sonra, "Türlerin karakteristik özellikleri” başlıklı bölümde verilen türlerin detaylı özellikleri ile karşılaştırıldıktan sonra nihai karar verilmelidir.

\section{Familya için tayin anahtarı (Bierri, 1991)}

1)-Baş kısmında çengeller var, fakat dişler bulunmaz Krohnittellidae; Bathyspadellidae

- Baş kısmında hem dişler, hem de çengeller mevcuttur...........................................2

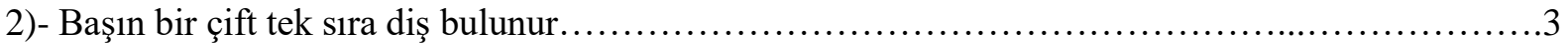

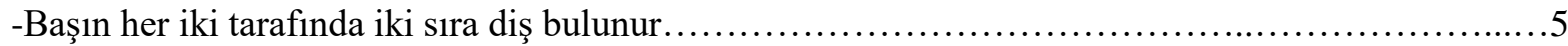

3)-Dişler çok belirgin, yelpaze şeklinde, geniş tabanı fan gibi üst üste binmiş şekildedir

........................................................................... Krohnittidae

-Dişler kama şeklinde yada uzun ve dar, tabanda belirgin bir genişleme yoktur..................................Bathybelosidae, Eukrohnia (Eukrohniidae), Spadellidae

4)-Ön ve arka yüzgeçler olmak üzere iki çift yüzgeç bulunur.............................Sagittidae -Vücudunda sadece bir çift yüzgeç bulunur........Heterokrohnia ve Archeterokrohnia Eukrohniidae

Türkiye kıyılarında yaşayan Krohnittidae ve Sagittidae familyasına ait ketognat türleri için tayin anahtarı

1)- Lateral yüzgeç iki çift

-Lateral yüzgeç bir çift, başın her iki yanında birer sıra dişler mevcut, yüzgeç çifti geniş, dış tarafta 1şınsız zona sahip, gövdenin arkasından kuyruk yüzgecine uzar. Yaka ve bağırsak divertikülü yoktur. Seminal kese, yan yüzgeçler ve kuyruk yüzgeci arasında uzamıştır (Şekil 2. A,B)

Krohnitta subtilis

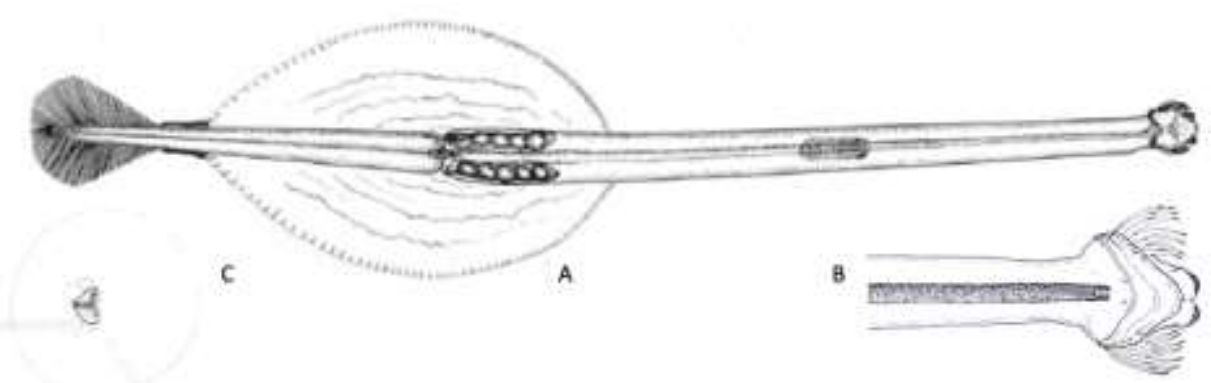

Şekil 2. A. Krohnitta subtilis'in genel görüntüsü, B. Baş ve dişlerin görünümü, C. Göz pigmenti pigmentinin görünümü (Mc lelland, 1989'dan).

2)-Vücut zayıf kas yapıl1, saydam, vücut sosis yada uzun balon şekilli şişkin ve kabarık, maksimum vücut genişliği vücudun orta bölgesinde olup, vücut genişliği başın yaklaşık 1.5 ila 2 katı

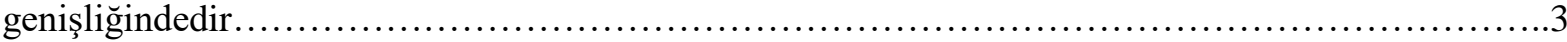

-Vücut katı, belirgin kaslı, yarı saydam. Birey zayıf kaslı ise vücut yaklaşık baş genişliğinde, kabarık ve şişkin değildir. Fasulye filizi şeklinde, maksimum vücut genişliğine yaklaşık vücudun ortasında ulaşır....

3)-Ön ve arka yüzgeçler birbirine oldukça yakın ve ince doku parçası (yüzgeç köprüsü) ile bağlı, vücut oldukça büyük, ön yüzgeçlerin başlangıcı ventral gangliyona ulaşır yada yakın konumda yakın bir yerde başlar. Vestibülar oluk yarık şeklinde, yüzgeçlerin her ikisinde de 1şınsız zona sahip, kuyruk yüzgeci genellikle 2 lobludur (Şekil 3. A,B).

Pseudosagitta lyra 

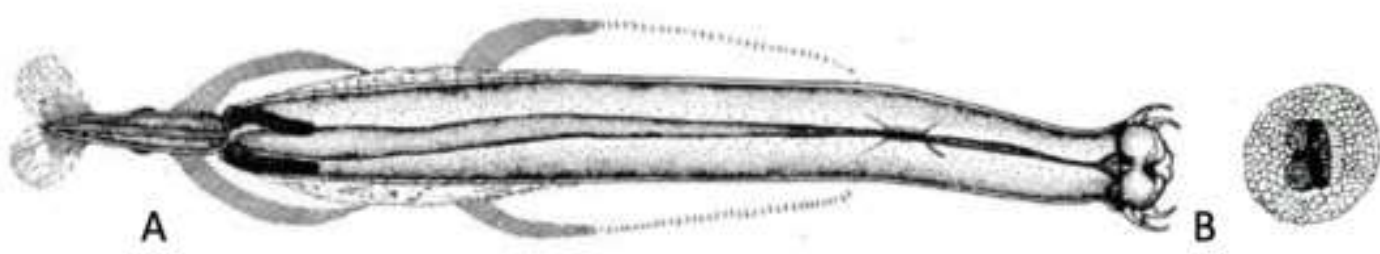

Şekil 3. A. Pseudosagitta lyra'nın genel görüntüsü (Mc lelland, 1989'dan),

B. Göz pigmentinin görüntüsü (Nair,2019'dan)

-Yüzgeçler arasında zarsı yüzgeç köprüsü yok, birbirlerinden belirgin şekilde ayrılmış, ön yüzgeçlerin başlangicı ventral gangliyonun oldukça gerisinde ve vestibülar oyuk dairesel șekillidir.

4)-Ön dişler 2-4 dışarıya firlamış, boyları $70 \mathrm{~mm}$ ye ulaşır, gözleri ince $T$ şekilli pigment beneklidir. Seminal kese küçük, yuvarlak ve kuyruk yüzgecine yakındır. (Şekil 4. A, B, C).

-Ön dişler dışarı fırlamamış, sayıları 4 den fazladır, boyları $30 \mathrm{~mm}$ ye ulaşır, gözleri yıldız şekilli pigment beneklidir. Kuyruk yüzgecinin bitiminde arka ucunda V şekilli materyal yığını var. Seminal kese kuyruk yüzgeciyle temas halindedir (Şekil 5. A, B ,C)

\section{Flacisagitta enflata}

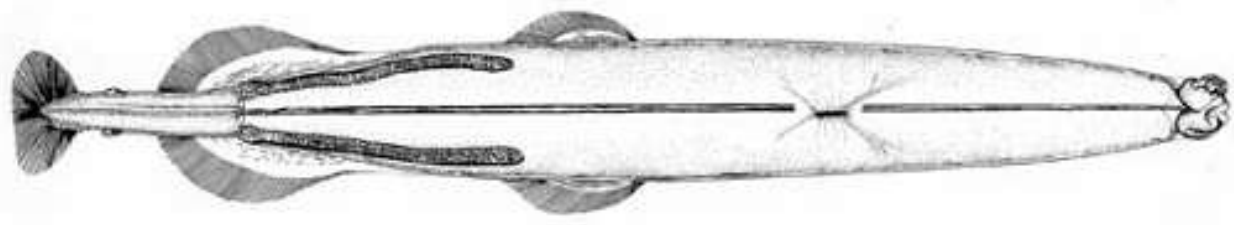

A

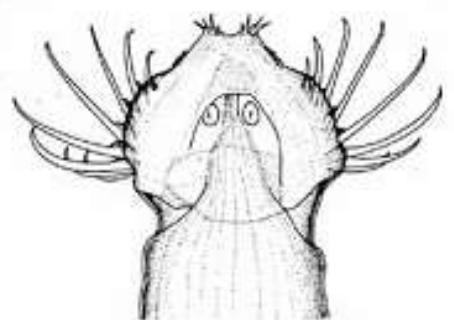

B

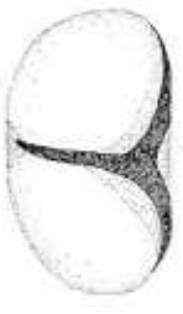

C

Şekil 4. A. Flacisagitta hexaptera'nın genel görüntüsü, B. F. hexaptera'nın baș kısmının görüntüsü, C. F. hexaptera'nın göz pigmentinin görünümü (Mc lelland, 1989'dan).
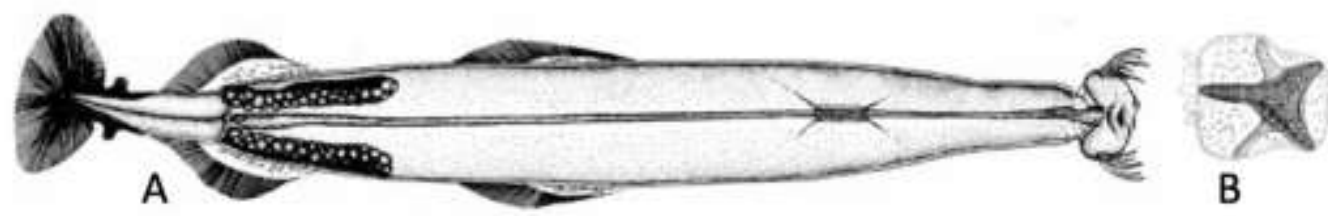

Şekil 5. A. Flacisagitta enflata'nın genel görüntüsü, B. Göz pigmentinin görüntüsü (Mc lelland, 1989'dan). 
5)-Çengellerin uçlarının iç kısımları düzdür (Şekil 6 A).

-Çengellerin iç kenarı yüzlük büyütmede bakıldığında girintili çıkıntılıdır (Şekil 6 B), ön yüzgeçler ventral gangliyonun arka ucundaki seviyede başlar. Her iki yüzgeçte de ş̧ınsız zon bulunur. Seminal kese arka yüzgeçler ile bitişik, kuyruk yüzgecinden ayrılmıştır. Bağırsak divertikülü yok, yaka yok ya da gelişmemiş, yumurta tek sıra olgunlukta ön yüzgece ulaşır. Gözler uzamış ' $\mathrm{T}$ ' şekilli pigment beneklerine sahiptir (Şekil 7.A,B,C).

Serratosagitta serratodentata

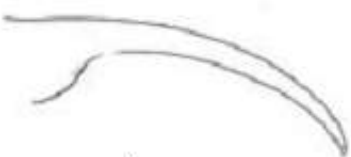

A

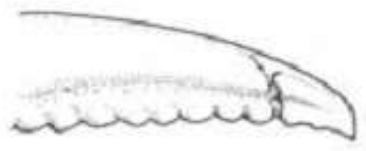

B

Şekil 6. A. Düz çengel ucu, B. Girintili çıkıntılı çengel ucu (Mc lelland, 1989'dan).
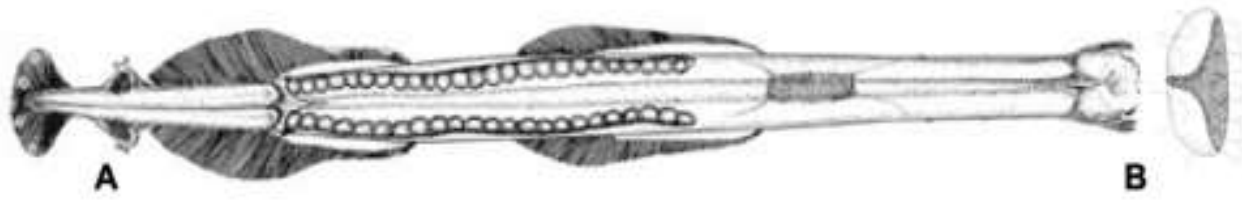

Şekil 7. A. Serratosagitta serratodentata'nın genel görüntüsü, B. Göz pigmentinin görüntüsü (Mc Lelland, 1989'dan).

6)-Yaka yok yada gelişmemiştir.

-Yaka var.

7)-Bağırsak divertikülü bulunmaz, yüzgeçler tamamen 1şınlı, ön yüzgeçler ventral gangliyon seviyesinin oldukça aşağısında başlar, seminal kese arka yüzgece ve kuyruk yüzgecine yakın ya da olgunlukta her ikisine de bitişik olabilir. Yumurtalıklar kısa ön yüzgecin arka ucuna ulaşır (Şekil 8)

Parasagitta setosa

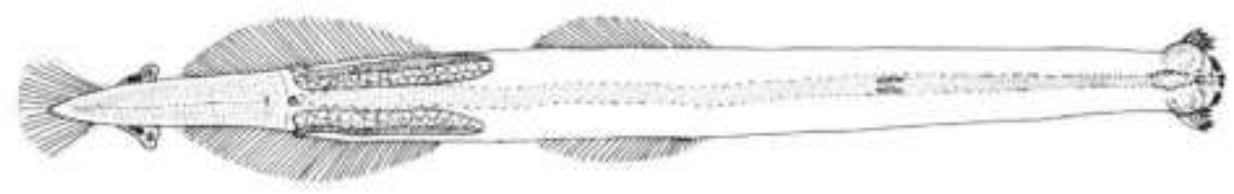

Şekil 8. Parasagitta setosa'nın genel görüntüsü (Peijnenburg, 2004'den).

-Bağırsak divertikülü mevcut.

8)-Bağırsak divertikülü küçük, yüzgeçler kısmen 1şınlı, dış tarafında seyrek 1şınlar bulunur. Yumurtalıklar kısa olup, birkaç yumurta bulunur. Seminal kese kuyruk yüzgecine bitişik, arka yüzgeçlerden ayrılmıştır. Gözler, $\mathrm{T}$ şekilli pigment beneklerine sahiptir (Şekil 9. A, B). Mesosagitta minima 


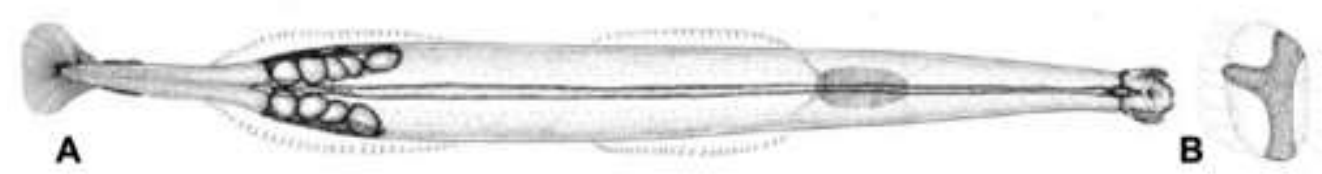

Şekil 9. A. Mesosagitta minima’nın genel görüntüsü, B. Göz pigmentinin görüntüsü (Mc lelland, 1989’dan).

-Bağırsak divertikülü büyük, yüzgeçler tamamen 1şınlı, göz pigmenti T şeklinde olup, üç uzantısı da eşittir. Seminal kese Kuyruk yüzgeci ve arka yüzgeçlere bitişik değildir (Şekil 10. A, B)

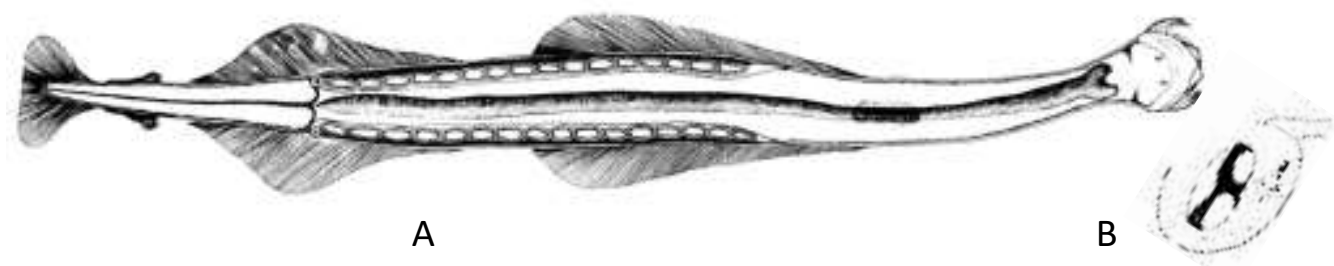

Şekil 10. A. Decipisagitta decipiens'in genel görüntüsü, B. Göz pigmenti.

9)-Bağırsak divertikülü yok yada gelişmemiş.

-Bağırsak divertikülü belirgin, seminal kese kuyruk yüzgecine ve arka yüzgeçlere bitişik, yumurtalıklar boyun bölgesine ulaşır. Gözler $\mathrm{T}$ şekilli pigment beneklerine sahiptir (Şekil 11. A, B.

Ferosagitta galerita

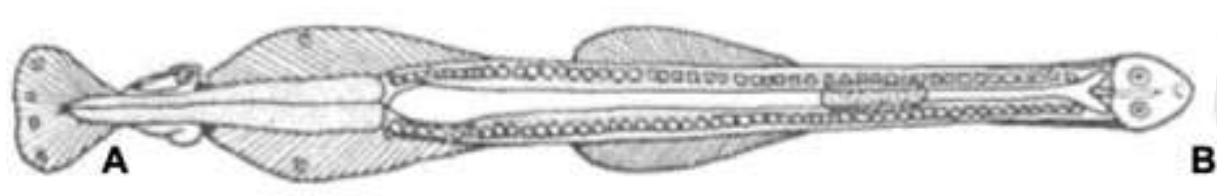

Şekil 11. A. Ferosagitta galerita'nın genel görüntüsü, B. Göz pigmentinin görüntüsü (Dallot, 1971'den).

10)-Seminal kese arka yüzgeçlerden belirgin şekilde ayrılmış.

.11

-Seminal kese arka yüzgeçlere bitişik.

11)-Yaka iyi gelişmiş, tüm gövdeyi kaplar. Gözler küçük, yumurtalıklar ventral gangliyon bölgesine ulaşır, yumurta büyük bir ya da iki sıralı, seminal kese küçük, ön kısmı belirgin şekilde yuvarlak, kuyruk yüzgeci ile bitişiktir. Gözler küçük ve hafifçe uzamıştır (Şekil 12. A, B)...
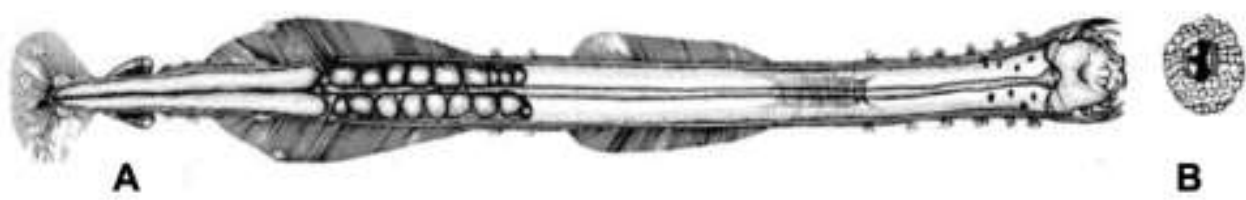

Şekil 12. A. Sagitta bibunctata'nın genel görüntüsü (Mc lelland, 1989'dan), B. Göz pigmentinin görüntüsü (Nair, 2019b'dan). 
-Yaka sadece boyunda bulunur. Ön yüzgeçler ventral gangliyonun arka ucundan gangliyonun yarıs1 kadar uzunluğunda bir arayla başlar, seminal kese kuyruğa yakın fakat bitişik değildir. Ön dişlerin sayısı arka dişlerden daha azdır. Yumurtalıklar ön yüzgecin ön ucuna kadar ulaşabilir. Gözler T şekilli pigment beneklere sahiptir (Şekil 13. A,B).

Parasagitta megalophthalma
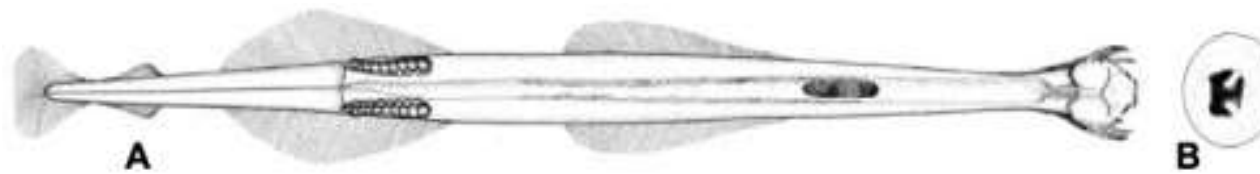

Şekil 13. A. Parasagitta megalophthalma’nın genel görüntüsü, B. Göz pigmentinin görüntüsü (Mc lelland, 1989'dan).

12)-Yaka küçük, erginlerde yumurta küçük ve çok sayıda çoğunlukla ön yüzgeçlerin orta noktasına kadar ulaşabilir, seminal kesenin ön tarafı şişkindir, boy $15 \mathrm{~mm}$ ye ulaşır. Gözler köşelidir (Şekil 14. A, B). Parasagitta friderici

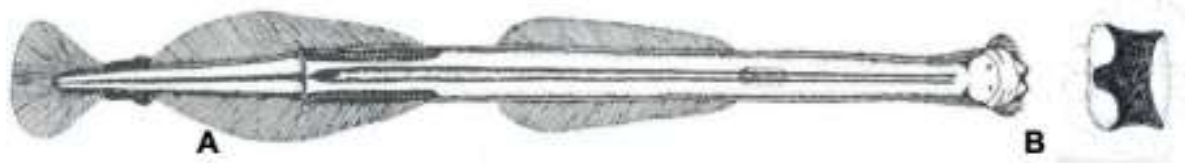

Şekil 14. A. Parasagitta friderici’nin genel görüntüsü, B. Göz pigmentinin görüntüsü (Mc lelland, 1989'dan).

-Yaka gelişmiş, yumurta büyük ve çok sayıda değil, genellikle ön yüzgece uzamaz, seminal kese oval, boyu $8 \mathrm{~mm}$ den az, gözler köşelidir (Şekil 15. A, B).

Parasagitta tenuis

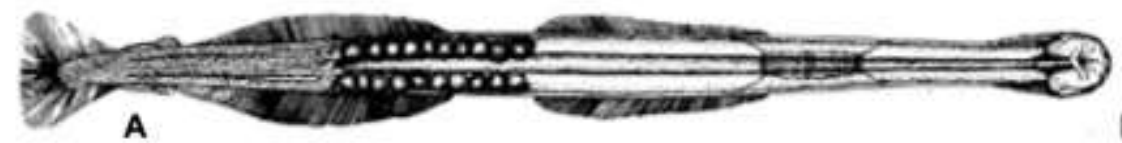

B

Şekil 15. A. Parasagitta tenuis'in genel görüntüsü, B. Göz pigmentinin görüntüsü (Mc lelland, 1989'dan).

\section{Türlerin karakteristik özellikleri}

Familya: Krohnittidae Tokioka, 1965

Cins: Krohnitta Ritter-Záhony, 1910

Krohnitta subtilis (Grassi, 1881)

Vücutları zayıf ve şeffaf, baş küçük boyun bölgesinde çok az farkla genişlemiş, gözleri yuvarlak pigment beneklidir (Şekil 2. B) Kuyruk ve gövde kısmında konumlanmış bir çift yan yüzgeçlere sahiptir. Yüzgeçlerin büyük bir kısmı ışınsız zon içerir. Yaka ve bağırsak divertikülü yoktur. Yumurtalıklar kısa, yumurta büyüktür. Seminal kese, kuyruk yüzgeci ve yan yüzgeçler arasında uzamıştır (Şekil 2. A) (Pierrot- Bults ve Chidgey, 1988).

Olgunlaşmış bireylerin vücut uzunluğu 12-16 mm, çengellerin sayısı 7-9, tek sıralı dişlerin sayısı 912 'dir. Kuyruk bölgesinin uzunluğunun toplam vücut uzunluğuna oranı \% 31-40'tır (Mc lelland, 1989).

Ekolojisi: Oseanik, alt epiplanktonik ya da üst mezoplanktoniktir (Kehayias vd., 1999).

Familya: Sagittidae Claus and Groben, 1905

Cins: Decipisagitta Bieri, 1991

Decipisagitta decipiens (Fowler, 1905)

Vücut ince, yarı saydam, yumuşak, yumurtalıkların bulunduğu bölgede en geniştir (Şekil 10. A). Baş küçük olup, gövdeden belirgin bir boyun ile ayrılır. Gözler oval şekilli olup, pigmenti üç dallı görülmektedir (Şekil 10. B). Enine olan pigment dalı boyuna olanlardan göreceli olarak kısadır. 
Bağırsak divertikülü mevcut olup, iyi gelişmiştir. Ön yüzgeçler ventral gangliyonun neredeyse arka ucunun yarısına gelir. Göreceli olarak arka yüzgeçlerden daha uzundur ve tamamen 1şınlıdır. Arka yüzgeçler üçgen şekilli, kuyruk bölmesinde en geniştir. Yüzgeçlerin çoğunluğu gövdede konumlanmıştır. Yumurta kanalının açıklığının bulunduğu alandaki küçük kısım hariç tamamıyla 1şınlıdır. Yumurtalıklar ön yüzgeçlerin ön ucuna doğru uzamıştır. Yumurta oval, silindirik ve tek sıralıdır. Seminal kese ön bölgesi en geniş olmak üzere armut şekillidir. Arka ve kuyruk yüzgecinden belirgin bir şekilde ayrılmış olup, kuyruk yüzgecine daha yakındır (Alvarino, 1967). Olgun bireylerin uzunluğu 13-16 mm'dir. Çengellerin sayısı 5-8; ön dişler 8-10; arka dişler 19-22 sayıdadır. Kuyruk bölümü toplam vücudun yaklaşık \%25-29 kadarını oluşturur (Alvarino, 1967). Kaslar görünür, fakat zayiftır.

Ekolojisi: Mesopelajik, açık deniz bölgeleri tercih eder. Levant ara suyunun indikatörüdür (Furnestin 1979).

\section{Cins: Ferosagitta Kassatkina, 1971}

Ferosagitta galerita (Dallot, 1971)

Vücutları sert, katı ve mattır (Şekil 11. A). Gözler büyük, T şekilli pigment beneklerine sahiptir (Şekil 11. B). Ön yüzgeçler ventral gangliyonun arka ucundaki seviyeden başlar. Ön ve arka yüzgeçler tamamen 1şınlıdır. Bağırsak divertikülü mevcuttur. Boyun bölgesinde yaka oldukça belirgindir. Yumurtalıklar uzun olup ve boyun bölgesine kadar uzanır. Seminal kese yuvarlak, tepe ve uzamış gövde kısmından oluşmuş olup, hem arka yüzgeçlere hem de kuyruk yüzgecine bitişik bulunur (Terbıyık vd., 2007; Dallot, 1971). Çengellerin sayısı 6-7, ön dişlerin sayısı, 4-8 arka dişlerin sayısı 8-13 civarındadır. Olgun bireylerin boyları: 11- $12 \mathrm{~mm}$. Kuyruk bölümünün toplam vücut uzunluğuna oranı \%26 ile 30 arasında değişir (Terbıyık vd., 2007).

Ekolojisi: Epipelajik, neritiktir (Dallot, 1971).

\section{Cins: Flaccisagitta Tokioka, 1965}

Flaccisagitta enflata (Grassi, 1881)

Vücutları yumuşak ve saydam, baş geniş ve belirgin bir boyun bölgesiyle gövdeden ayrılmıştır (Şekil 5. A).Bağırsak divertikülü ve yaka bulunmaz. Ön yüzgeçler kısa ve 1şınsız zona sahiptir, ventral gangliyonun arka ucundan oldukça geride başlar. Arka yüzgeçler ise geniş ve yuvarlaktır, 1şınsız zona sahiptir. Göz pigmentleri yıldız şeklindedir (Şekil 5. B). Yumurtalıklar olgunlaşmış bireylerde genellikle kısadır, bazen ön yüzgeçlerin arka ucuna doğru uzanabilir, yumurta küçük ve birkaç sıralıdır. Seminal kese küçük, yuvarlaktır, kuyruk yüzgecine bitişik bulunur (Şekil 5. A) (Alvarino, 1967). Olgun bireylerin uzunluğu: 6-25 mm dir (Alvarino, 1967). Çengellerin sayısı 8-11, ön dişlerin sayısı 6-11, arka dişlerin sayısı 16'ya ulaşır, kuyruk bölgesinin uzunluğunun toplam vücut uzunluğuna oran1 \% 14-18'dir (Mc lelland, 1989).

Ekolojisi: Epipelajik, neritik ve oşeanik (Kehayias vd., 1999)

\section{Flaccisagitta hexaptera (d'Õrbigny, 1836)}

Vücutları saydam ve yumuşaktır. Ön yüzgeçler yuvarlak ve kısmen 1şınlıdır, belirgin arayla ventral gangliyonun arka ucunun gerisinden başlar (Şekil 4. A). Arka yüzgeçler köşeli ve kısmen 1şınlıdır. Göz pigmentleri T şekillidir (Şekil 4. C). Yaka ve bağırsak divertikülü bulunmaz, olgun yumurtalıklar bazen ventral gangliyona kadar ulaşabilir ve yumurta küçük 3 sıralıdır, seminal keseler yuvarlak ve küçük, kuyruk yüzgecine yakın konumlanmıştır (Mc lelland, 1989). Olgunlukta vücut uzunluğu 38-40 mm olup, çengeller 6-10, ön dişler 3-6, arka dişler 3-8 sayıdadır. Kuyruk bölgesinin uzunluğunun toplam vücut uzunluğuna oranı \% 17-20'dir (Mc lelland, 1989).

Ekolojisi: Oseanik, epi- ve mesopelajik olup, bazen sığ kıyısal sularda da bulunabilir (Kehayias vd., 1999)

\section{Cins: Mesosagitta Tokioka, 1965}

\section{Mesosagitta minima (Grassi, 1881)}

Vücutları küçük, ince olup, küçük bir başa sahiptirler. Ön yüzgeçler ventral gangliyonun biraz gerisinde başlar, küçüktür. Göz pigmenti uzamış T şeklindedir (Şekil 9. B).Arka yüzgeçler daha çok gövde kısmında konumlanmıştır. İkisi de büyük ölçüde ışınsız zona sahiptir. Yaka yoktur. Bağırsak divertikülü bulunur. Yumurtalıklar çok kısa olup, içinde 4-5 tane büyük yumurta vardır. Seminal kese ovaldir. Arka yüzgeçlerden belirgin şekilde ayrılmış olup, kuyruk yüzgeciyle bitişiktir (Şekil 9. A) (Mc lelland, 1989). Olgun bireylerin vücut uzunluğu 14- $20 \mathrm{~mm}$. Çengeller 6, ön dişler 7-9, arka dişler 
14-20dir. Kuyruk bölgesinin uzunluğunun toplam vücut uzunluğuna oranı \% 19-27 dir (Mc lelland, 1989).

Ekolojisi: Oseanik ve neritik bir tür olup, oseanik ve kıyısal suların karıştığı bölgelerde yoğun olarak bulunur (Kehayias vd., 1999).

\section{Cins: Parasagitta Tokioka, 1965}

\section{Parasagitta friderici (Ritter-Záhony, 1911)}

Vücut oldukça katı ve mattır. Ön yüzgeçler kısa ve ventral gangliyonun arka ucundaki seviyede başlar. Arka yüzgeçler gövdede ve kuyruk kısmında eşit konumlanmıştır. İkisi de tamamen 1şınlıdır. Yaka kısa ve sadece boyun bölgesinde vardır. Yumurtalıklar ön yüzgece doğru uzanır, yumurta 2 sıralıdır. Olgunlaşmış seminal keseler yuvarlak ön bölge ve gövde olarak şekillenmiş olup, hem kuyruk yüzgecine hem de arka yüzgeçlere bitişiktir (Mc lelland, 1989) (Şekil 14. A). Gözler köşeli yapıdadır. Olgunlaşmış bireylerin boyu: 9-13 mm'dir. Çengellerin sayısı 7-9, ön dişlerin sayısı 5-9, arka dişlerin sayısı 22'ye ulaşır. Kuyruk bölgesinin uzunluğunun toplam vücut uzunluğuna oranı \% 25-30'dur (Mc lelland, 1989).

Ekolojisi: Neritik ve epiplanktonik, düşük tuzluluktaki kıyısal suları tercih ederler (Kehayias vd., 1999).

\section{Parasagitta megalophthalma (Dallot and Ducret, 1969)}

Vücut ince, baş nispeten büyüktür. Ön yüzgeçlerin uçları yuvarlak tamamen 1şınlı, ventral gangliyondan çok az ara ile geride başlar. Arka yüzgeçlerin uçları yuvarlak ve tamamen 1şınlıdır. Boyun bölgesinde yaka bulunur. Bağırsak divertikülüne benzer küçük bir yapı vardır. Olgunlaşmış bireylerde yumurtalıklar arka yüzgeçlerin ön ucuna uzanır, yumurta küçük ve çok sıralıdır. Seminal kese arka yüzgeçlerden belirgin şekilde ayrılmış, kuyruk yüzgecine çok yakın ya da bitişiktir (Şekil 13. A). Gözler belirgin olarak büyük ve dikdörtgen biçimindedir (Mc lelland, 1989). (Şekil 13 B). Olgun bireylerin boy uzunluğu 19.5 mm'ye ulaşır. Çengeller 7-8, ön dişler 5-8, arka dişler 13-21 sayıdadır ve kuyruk bölgesinin uzunluğunun toplam vücut uzunluğuna oranı \% 22-19'dur (Mc lelland, 1989).

Ekolojisi: Oseanik, epipelajik veya mezopelajiktir (Kehayias vd., 1999).

\section{Parasagitta setosa (J. Müller, 1847)}

Vücut küçük, dar, esnek ve saydam, baş küçüktür. Yüzgeçler yuvarlak ve tamamen 1şınlıdır. Ön yüzgeçler ventral gangliyondan biraz ara ile başlar, yaka yok ya da çok küçük, bağırsak divertikülü bulunmaz (Şekil 8. A). Gözler yıldız şekilli pigment beneklerine sahiptir (Şekil 8 B). Yumurtalıklar kısa, yumurta nispeten büyüktür, seminal kese arka yüzgeçlere yakın ya da bitişik, kuyruk yüzgecinden ayrılmıştır, uzamış gövde ve ön tepecikten oluşur (Pierrot-Bult ve Chidgey, 1988). Vücut uzunluğu 14 mmdir, çengeller 8-9, ön dişler 6-8, arka dişler, 10-16 sayıdadır. Kuyruk bölgesinin uzunluğunun toplam vücut uzunluğuna oranı \% 16-25'dir (Pierrot-Bult \& Chidgey, 1988).

Ekolojisi: neritik, epipelajik düşük tuzluluğa sahip kıyısal suları tercih eder (Kehayias vd., 1999).

\section{Parasagitta tenuis (Conant, 1896)}

Vücutları ince ve serttir. Ön yüzgeçler tamamen 1şınlı ventral gangliyonun arka ucundaki seviyeden başlar. Arka yüzgeçler tamamen ışınlı ve köşeli yapıdadır. Boyun bölgesinde yaka bulunur. Bağırsak divertikülü yoktur. Olgunluk aşamasında yumurtalıklar arka yüzgeçlerin ön ucuna ulaşır. Yumurta büyük, yuvarlak ve bir sıralıdır. Seminal kese ön dairesel bölge ve uzamış gövde kısmından oluşmuş olup, olgunlaşmış bireylerde hem kuyruk yüzgecine hem de arka yüzgeçlere bitişiktir (Şekil $15 \mathrm{~A}$ ). Gözler köşeli şekilde pigmentlere sahiptir (Mc lelland, 1989). (Şekil 15 B). Olgun bireylerin vücut uzunluğu, 7mm den küçüktür. Çengeller 6-9, Ön dişler 6-7, arka dişler 13-19 sayıdadır (Casanova, 1999). Kuyruk bölgesinin uzunluğunun toplam vücut uzunluğuna oranı \% 24-32'dir. (Mc Lelland, 1989).

Ekolojisi: Neritik ve epiplanktoniktir (Mc lelland, 1989).

Cins: Pseudosagitta Germain \& Joubin, 1912

Pseudosagitta lyra (Krohn, 1853)

Vücutları saydam ve yumuşaktır. Ön yüzgeçler uzun ve yuvarlak, ventral ganliyonun arka ucundaki seviyeden başlar (Şekil 3. A). Arka yüzgeçler ise köşelidir. Gözler uzamış Y şekilli pigmentlere sahiptir (Şekil 3. B) Ön ve arka yüzgeçler yüzgeç köprüsü ile bir birbirlerine bağlıdır. Bağırsak 
divertikülü ve yaka bulunmaz. Kuyruk yüzgeci 2 lopludur. Yumurtalıklar uzun, yumurta küçük ve çok sıralıdır. Seminal kese oval ve arka yüzgeçlere yakın olarak konumlanmıştır (Şekil 3. A). Yumurtalıklar ön yüzgecin ortasına ulaşır, yumurta küçük, 4 sıralıdır, seminal kese arka yüzgece yakın fakat bitişik değildir (Şekil 3.A) (Mc Lelland, 1989). Olgun bireylerin vücut uzunluğu: 30 - 38 mm'dir. Çengellerin sayısı 3-9, ön dişlerin sayısı 3-8, arka dişlerin sayısı 10'a ulaşır. Kuyruk bölgesinin uzunluğunun toplam vücut uzunluğuna oranı \% 15-20'dir (Mc Lelland, 1989).

Ekolojisi: Mesopelajik, açık deniz bölgelerini tercih eder (Furnestin, 1979), bazen akıntılarla kıyısal bölgelere yakın yerlere taşınabilir.

\section{Cins: Sagitta Quoy \& Gaimard, 1827}

\section{Sagitta bipunctata Quoy and Gaimard, 1827}

Vücut katı ve mat, ön yüzgeçler yuvarlak, tamamen 1şınlı ve ventral gangliyonun arka ucundaki seviyede başlar (Şekil 11. A). Gözler hafifçe uzamış pigmentlere sahiptir (Şekil 11. B). Arka yüzgeçler de hafif köşeli ve tamamen 1şınlıdır. Yaka oldukça gelişmiş olup, vücut uzunluğu boyunca arkaya doğru uzar. Bağırsak divertikülü yoktur. Yumurtalıklar ön yüzgeçlerin arka ucunu geçerek öne doğru uzamıştır. Seminal kese yuvarlak tepe ve uzamış gövde kısmından meydana gelmiş olup, kuyruk yüzgecine bitişiktir, fakat arka yüzgeçlerden belirgin şekilde ayrılmıştır. Arka yüzgeçlerle seminal kese arasında yumuşak ince doku paçası bulunmaktadır (Mc lelland, 1989) (Şekil 11. A). Olgunlaşmış bireyin vücut uzunluğu 10-15 mm arasındadır. Çengellerin sayısı 8-11, ön dişlerin sayısı 5-7 ve arka yüzgeçlerin sayısı 17'ye ulaşır, kuyruk bölgesinin uzunluğunun toplam vücut uzunluğuna oranı \% 2427'dir (Mc lelland, 1989).

Ekolojisi: Oşeanik ve epipelajiktir. Tuzluluğun yüksek olduğu açık deniz sularını tercih ederler (Kehayias vd. 1999).

\section{Cins: Serratosagitta Tokioka, 1965}

\section{Serratosagitta serratodentata (Krohn, 1853)}

Vücut ince, katı ve mattır. Çengellerin içlerinde girintili çıkıntılı yapı bulunur (Şekil 7. B). Boyun bölgesinde küçük bir yaka görünebilir. Ön yüzgeçler köşeli, ışınsız zona sahip ve ventral gangliyonun arka ucundaki seviyede başlar. Arka yüzgeçler uzun, köşeli ışınsız zona sahiptir. Yaka yok ya da gelişmemiştir. Bağırsak divertikülü yoktur. Yumurtalıklar olgunlukta ön yüzgeçlerin başlangıcına kadar ulaşır (Michel, 1984). Yumurta küçük ve tek sıradır. Seminal kesenin ön tarafında yanlarda 2 papilla bulunur, arka yüzgeçlere bitişik olup kuyruk yüzgecinden ayrılmıştır (Şekil 7. A). Gözler uzamış T şekilli pigment beneklerine sahiptir (Mc Lelland,1989). (Şekil 7. B). Olgun bireylerin vücut uzunluğu: 10-13 mm arasındadır. Çengeller 5-8, ön dişler 6-10, arka dişler 15-20 saysıdadır. Kuyruk bölgesinin uzunluğunun toplam vücut uzunluğuna oranı \% 23-28'dir (Mc Lelland,1989).

Ekolojisi: Oseanik ve epiplanktonik bir türdür (Michael, 1984).

Teşekkür: Kaynak elde etme konusunda yardımları olan George Kehayias, Erik Thuesen ve Mc Lelland'a burada teşekkürlerimizi sunarı.

\section{KAYNAKLAR}

Alvarino, A. (1967). The Chaetognatha of the Naga Expedition (1959-1961) in the South ChinaSea and the Gulf of Thailand, Naga Report, 4(2), 1-197.

Beşiktepe, Ş., \& Ünsal, M. (2000). Population structure, vertical distribution and diel migration of Sagitta setosa (Chaetognatha) in the South- western part of the Black Sea. Journal of Plankton Research, 22(4), 669683.

Bieri, R. (1991). Systematics of the Chaetognatha. In Q. Bone, H. Kapp \& A. C. Pierrot-Bults (Eds.), The Biology of Chaetognaths (pp.122-136). Oxford: Oxford University Press.

Casanova, J. P. (1985). Description de L'appareil genital primitive du genre Eukrohnia et nouvelle classification des chaetognathes. Compte rendu de l'Academie des Sciences, 301(11), 397-402.

Casanova, J.P. (1999). Chaetognatha. In D. Boltovskoy (Ed.), South Atlantic Zooplankton (pp.1353-1374). Leiden: Backhuys Publishers.

Conway, D.V.P. (2015). Marine zooplankton of southern Britain. Part 3: Ostracoda, Stomatopoda, Nebaliacea, Mysida, Amphipoda, Isopoda, Cumacea, Euphausiacea, Decapoda, Annelida, Tardigrada, Nematoda, Phoronida, Bryozoa, Entoprocta, Brachiopoda, Echinodermata, Chaetognatha, Hemichordata and Chordata. In A.W.G. John (Ed.). Plymouth: Marine Biological Association of the United Kingdom.

Dallot, S., (1970). L'Anatomie du tube digestif dans la phylogenie et la systematique des chaetognathes. Bulletin 
du Museum National d'Histoire Naturelle, 42, 549-565.

Dallot, S., (1971). Les chaetognathes de Nosy Bé: description de Sagitta galerita sp.n. Bulletin Zoölogisch Museum Universiteit van Amsterdam, 2, 13-18.

Fraser, J. H. (1957). Chaetognatha. Zooplankton, sheet 1, Conseil international pour l'exploration de la mer, Paris.

Furnestin, M. L. (1957). Chaetognathes et zooplancton du secteur Atlantique marocoin. Revue des Travaux de l'Institut des Peches Maritimes. 21 (1-2), 1-356.

Hazar, D. (2006). İskenderun Körfezi'nde bulunan ketognat (Sagittidae) türlerinin taksonomisi ve genetik analizi. Mustafa Kemal Üniversitesi, Fen Bilimleri Enstitüsü, Yüksek Lisans Tezi, Hatay.

Hyman, L.H. (1959). The Invertebrates. Vol. 5. McGraw-Hill Company, Newyork.

İşmen, P. (2000). İskenderun Körfezi’nde ketognat dağılımı ve topluluk yapısı. Mustafa Kemal Üniversitesi, Fen Bilimleri Enstitüsü, Yüksek Lisans Tezi, Hatay.

Kasatkina, A.P. (1982). Chaetognaths of the Seas of USSR and Adjacent Waters. Nauka Leningrad.

Kehayias, G., Fragopoulu, N., \& Lykakis. J. (1999). An identification key for the chaetognath species of the Mediterranean Sea. Biologia Gallo-Hellenica, 25, 105-124.

Kurt, T., 2016. Kuzeydoğu Akdeniz, Türk Boğazlar Sistemi ve Karadeniz mesozooplankton topluluklarının bölgesel değişimi. Çukurova Üniversitesi, Fen Bilimleri Enstitüsü, Doktora Tezi, Adana.

Mc Lelland, J.A. (1989) An illustrated key to the Chaetognathaof the northern Gulf of Mexico with notes on the their distribution. Gulf Research Reports, 8, 145-172.

Michel, H.B. (1984). Chaetognatha of the Caribbean Sea and Adjacent Areas. NOAA NMFS, 1- 33 Technical Report 15.

Mutlu, E. (2006). Diel vertical migration of Sagitta setosa asinferred acoustically in the Black Sea. Marine Biology. 149 (3), 573-584.

Nair, V. R. (2019a). http://www.niobioinformatics.in/pdf/cheatognaths/Cheatognaths_19.pdf. Erişim tarihi: 25.05.2018.

Nair, V. R. (2019b). http://www.niobioinformatics.in/pdf/cheatognaths/Cheatognaths_12.pdf. Erişim tarihi: 25.05 .2018

Owre, H. B. (1973). A new Chaetognath genus and species, with remarks on the taxonomyand distribution of others. Bulletin of Marine Science, 23, 948-963.

Peijnenburg K.T.C.A., \& Pierrot- Bults, A.C. (2004). Quantitative morphological variation in Sagitta setosa Müller 1847 (Chaetognatha) and two closely related taxa. Zoology, 74, 305- 315.

Pierott- Bults, A.C., \& Chidgey K.C. (1988). Chaetognatha. Synopses of the British Fauna (New Series) 39, 166.

Reeve, M.R. (1970). I. Quantitative aspects of growth and egg production in Sagitta hispida. In G. H. Steele (Ed.) Marine food chains, pp(168-189), Edinburgh: Oliver Boyd.

Szaniawski, H. (2002). New evidence for protoconodont origin of chaetognaths. Acta Palaeontologica Polonica 47(3), 405- 419.

Terbıyık Kurt, T. (2018). İskenderun Körfezi (Kuzeydoğu Akdeniz) Kıyısal Sularında Flaccisagitta enflata (Grassi, 1881)’nın Beslenmesi ve Bağırsak İçeriği Üzerine İlk Gözlemler. Kahramanmaraş Sütçü İmam Üniversitesi Tarım ve Doğa Dergisi, 21(5), 765-771.

Terbıyık Kurt, \& T., Polat, S. (2013). Seasonal distribution of coastal mesozooplankton community in relation to the environmental factors in Iskenderun Bay (north-east Levantine, Mediterranean Sea). Journal of the Marine Biological Association of the United Kingdom, 93, 1163-1174.

Terbıyık, T., Çevik, C., Toklu-Alıçlı, B., \& Sarıhan, E. (2007). First record of Ferosagitta galerita (Dallot, 1971) [Chaetognatha] in the Mediterranean Sea. Journal of Plankton Research, 29(8), 721-726.

Terbıyı, T., \& Sarıhan, E., (2008). Seasonal distribution of species composition and abundance of chaetognaths in the Yumurtalik Inlet (Adana). Çukurova Üniversitesi Fen ve Mühendislik Bilimleri Dergisi, 17(8), 9095.

Tregouboff, G., \& Rose, M. (1957). Manuel de Planctonologie Mediterranenne. Centre National de la Recherche Scientifique, Paris.

Üstün, F. (2005). Karadeniz'in Sinop burnu bölgesinin zooplankton kompozisyonu ve mevsimsel dağılımı. 19 Mayıs Üniversitesi, Fen Bilimleri Enstitüsü, Yüksek Lisans Tezi, Samsun.

Zgong, Z. (1988). Marine Planktonology. Ocean Press, China.

Zhang, G., \& Chen, O. C. (1983). Studies on chaetognathas in central and northern parts of South China Sea. Contributions on marine biological research of the South China Sea, 1, 17-63. 